Çukurova Üniversitesi Mühendislik Mimarlık Fakültesi Dergisi, 33(1), ss. 209-218, Mart 2018

Çukurova University Journal of the Faculty of Engineering and Architecture, 33(1), pp. 209-218, March 2018

\title{
Yüksek Isı Ortamının Otomat Çeliklerinin Yorulma Ömrüne Etkisinin İncelenmesi
}

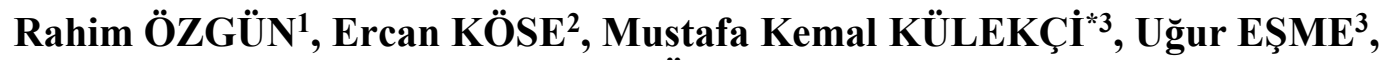 \\ Şeref ÖCALIR ${ }^{4}$
}

\author{
${ }^{1}$ İskenderun Demir ve Çelik A.Ş, Hatay \\ ${ }^{2}$ Mersin Üniversitesi, Tarsus Teknoloji Fakültesi, Mekatronik Mühendisliği Bölümü, Mersin \\ ${ }^{3}$ Mersin Üniversitesi, Tarsus Teknoloji Fakültesi, Otomotiv Mühendisliği Bölümü, Mersin \\ ${ }^{4}$ Mersin Üniversitesi, Fen Bilimleri Enstitüsü, İmalat Mühendisliği Anabilim Dal, Mersin
}

Geliş tarihi: $16.01 .2018 \quad$ Kabul tarihi: 14.03 .2018

$\ddot{\mathbf{O z}}$

Bu çalışmada yüksek ısı ortamının otomat çeliklerinin yorulma ömrüne etkisi incelenmiştir. Bu amaçla silindirik malzemelerde kullanılmak üzere mikro denetleyicili yorulma test cihazı tasarlanmıştır. Otomat çeliği $900^{\circ} \mathrm{C}$ ' de olmak üzere 3 saat bekletilmiştir. Yüksek 1sıda bekletilmiş ve bekletilmemiş numuneler; tasarımı ve imalatı yapılmış cihazda farklı gerilmelerde yorulma testine maruz bırakılarak, yüksek ısınının ilgili malzeme üzerinde yorulma ömrüne etkileri incelenmiştir. Deneyler sonucunda yüksek 1sı ortamının otomat çeliklerinde yorulma ömrünü kısalttığı gözlenmiştir. Ayrıca, deneyler sonucunda numunelerin kırılma yüzeylerinin, taramalı elektron mikroskobundan (SEM) alınan fotoğrafları incelendiğinde, yüksek 1sıda bekletilmiş numunelerin gözenek yoğunluğunun artmış olduğu tespit edilmiştir.

Anahtar Kelimeler: Yorulma testi, Otomat çeliği, Mikro denetleyici

\section{An Investigation of Effect of High Temperature Environmental to Fatigue Life of Cutting Steels}

\begin{abstract}
In this study, effects of high temperature environmental to fatigue life have been investigated in cutting steels. For this purpose, fatigue testing machine of micro controller was designed for cylindrical material. The samples which were produced from cutting steels had been kept in high temperature $\left(900{ }^{\circ} \mathrm{C}\right)$ for 3 hours. Effects of high temperature to fatigue life have been investigated by exposing the samples kept and non-kept in high temperature to fatigue test for different tensiles in designed and produced machine. As result of experiments, it has been observed that the high temperature environment has reduced fatigue resistance in cutting steels. Besides, it was determined that pore intensity of samples kept in high temperature environment increased when the photographs taken from scanning electron microscope (SEM) were investigated.
\end{abstract}

Keywords: Fatigue test, Cutting steel, Micro controller

*Sorumlu yazar (Corresponding author): Mustafa Kemal KÜLEKÇI, mkkulekci@yahoo.com 


\section{GíRiş}

Dinamik yüklere maruz kalan makine elemanlarında meydana gelen hasarların tamamına yakını yorulmadan kaynaklanmaktadır [1-6]. Makine elemanlarının yorulma ömrü, yüzey sertleştirme işlemleri ile geliştirilebilmektedir. Yorulma olaylarında çatlak oluşumu genellikle yüzeyde başlar. Çünkü eğme ve burma gerilmelerinin uygulandığı durumlarda en yüksek gerilme yüzeylerde oluşur. $\mathrm{Bu}$ nedenle malzemenin yorulma ömrünü arttırmak büyük ölçüde yüzey çatlaklarının oluşumunu engellemekle olur. Çatlağa engel olma yüzey özelliklerinin arttırılması ile mümkündür [6-7, 10-11].

Malzeme yorulma ömrünü tamamladığında, yüzeyde başlayan bu çatlaklar zamanla ilerleyerek malzemenin kırılmasına neden olur.

Bundan dolayı bir tasarımda, malzemenin yorulma toplam ömrü dikkate alınmaktadır. Fakat makine elemanları işletme şartlarında, çizikler ve çatlaklar gibi kusurlar içerebilir. Dinamik yükler altında çalışan yapısal elemanda, yorulma çatlağı bu kusurlardan başlayabilir [8-9]. Yorulma mukavemeti, parçaya belli bir tekrar sayısı (N) uygulandıktan sonra; parçayı kıracak gerilmedir. Yorulma mukavemeti tekrar sayısına bağlıdır [12].

Yorulma mukavemetini tekrar sayısı aracılığıyla değerlendirebilmek için; standart boyut ve yüzey özelliğine sahip malzemelere sabit bir gerilme ile yorulma testi yapılmaktadır. Yorulma deney sonuçları belirli koşullar için fikir verir ve benzer koşulların bulunabileceği parça tasarımında gerekli önlemlerin alınmasına yardımcı olur.

Yorulma deneylerinde kullanılan cihazlar; eksenel gerilme, eğme gerilmesi (düzlemsel veya dönen eğme gerilmesi), burma gerilmesi, birleşik gerilme uygulayanlar şeklindedir [12]. Deneye tabi tutulacak parça, çalışma esnasında ne tür gerilmelere uğrayacaksa, o tür gerilmelerin uygulandığı deney cihazının seçilmesi gerekir. Aksi takdirde elde edilen sonuçlar güvenilir olamaz.
Taşıtların akslarının yorulma ömürlerinin belirlenmesinde bahsedilen deney türlerinden dönen eğme gerilmeli yorulma testi kullanılması gerekir. Wöhler'i ilk defa yorulma üzerine çalışmaya iten durum da akslarda meydana gelen yorulmadır. Wöhler yayınladığı bir kitap ile malzemelerin gerilme yoğunluğunda artışa sebep olan form değişikliklerinin de değişken zorlama kadar önemli olduğu konusunda dikkat çekmiştir [13].

Yorulma deney sonuçları Wöhler diyagramı kullanılarak değerlendirilebilmektedir. Yorulma testine maruz birakılacak numunelerin, her biri farklı gerilmelerde kırılmanın oluştuğu tekrar sayıları saptanır. Bir deney serisinde tüm parçalar için ortalama gerilme sabit tutularak her deney için ayrı bir gerilme seçilir. İlk deney numunesinde en üst gerilme genellikle çekme dayanımına yakın olacak şekilde yüksek düzeyde zorlanır. Daha sonraki deney numuneleri, gittikçe daha düşük gerilme uygulanarak kırılma tekrar sayısının çok yüksek değerlere ulaşması sağlanır. Deneyler sonunda eğer tekrar sayıları büyük dağılmalar göstermiyorsa gerilme ve tekrar sayıları arasındaki ilişki Şekil 1'deki gibi Wöhler eğrisi elde edilir.

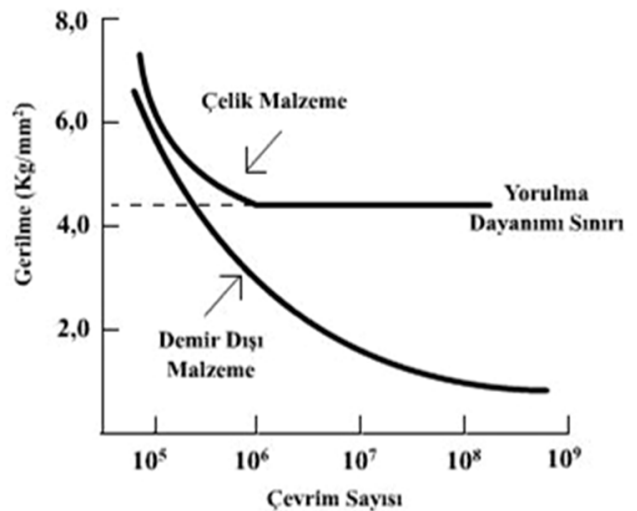

Şekil 1. Değişik malzemeler için wöhler diyagramı [1-7]

19. yüzyıl sonlarına doğru, Wöhler ile başlayan yorulma üzerine çalışmalar, günümüzde de devam etmektedir. Ülkemizde de yorulma test düzeneği tasarımı konusunda çok fazla çalışma olmasa da, yorulma ömrünün arttırılması veya incelenmesi üzerine birçok çalışma bulunmaktadır. 
Demet Gönen ve arkadaşları metalik yayların ömürlerini belirlemek üzere yorulma analizi yapmak amaciyla "Mekanik Yay Yorulma Test Cihazı" tasarlamış ve imalatını gerçekleştirmişlerdir [14]. Tekrar sayısını belirlemek için tasarıma bir mikro denetleyici de eklemişlerdir. İlgili çalışmada deney düzeneğine, test için belirli sayıdan oluşan iki grup yay bağlanabilmekte ve aynı deney süresince bu iki gruba biri diğerinden farklı olacak şekilde iki sıkıştırma oranı uygulanabilmektedir.

$\mathrm{Bu}$ çalışmada; devir/dakika ile dönen, eğme gerilmesine maruz kalan parçaların yorulma ömrünü belirlemede kullanılabilecek; mikro denetleyicili yorulma test cihazı tasarımı gerçekleştirilerek yüksek isı ortamının otomat çeliklerinin yorulma davranışına etkileri incelenmiştir.

\section{SISTEM TASARIMI VE DENEYSEL ÇALIŞMALAR}

\subsection{Mekanik Tasarım}

Bu çalışmada Şekil 2'de görüldüğü gibi tasarlanan sistemde numuneye hareketli ağırlık sayesinde bir gerilme uygulanarak, numunenin belirli bir gerilme altında, yüksek devirde dönmesi sağlanmıştır.

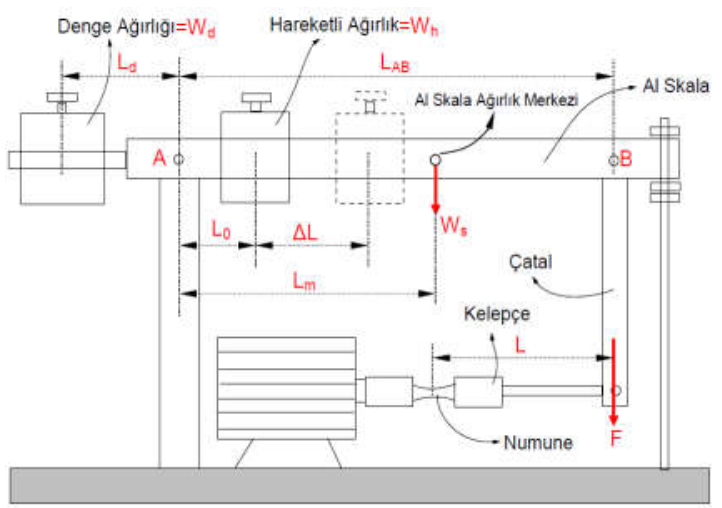

Şekil 2. Deney düzeneğinin şematik görünüşü

Şekil 2'de görülen denge ağırlığı sayesinde deney düzeneğinde terazi dengeye getirilerek gerilmenin sıfır olması sağlanabilmiştir. Hareketli ağırlık A noktasından uzaklaştıkça, numune üzerinde ne kadar bir gerilme kuvveti uygulanabileceği hesaplanabilmiştir.

Teorik olarak sistem dengedeyken denge ağırlığının (Wd) A noktasından itibaren mesafesi, A noktasına göre moment alarak tayin edilir. $\mathrm{Bu}$ hesaplamayı yapabilmek için sistem üzerindeki dengeleme ağırlığı (Wd), hareketli ağırlık (Wh), skala kolu ağırlığı (Ws), çatal, bağlı olan mil ve mandrenin (Wk) ağırlığına ihtiyaç vardır.

İlgili elemanların ağırlıkları aşağıdaki gibi ölçülmüştür.
Wd: 5050 gram
Ld: ?
Ws: 2600 gram
Lm: $268,43 \mathrm{~mm}$
Wh: 2000 gram
Lo: $25 \mathrm{~mm}$
Wk: 1150gram
LAB: $600 \mathrm{~mm}$

A noktasına göre moment alırsak:

$\Sigma \mathrm{MA}=0$

$\mathrm{Wd} \times \mathrm{Ld}-\mathrm{Wh} \times \mathrm{Lo}-\mathrm{Ws} \times \mathrm{Lm}-\mathrm{Wk} \times \mathrm{LAB}=0$

$5050 \times$ Ld $-2000 \times 25 \times 2600 \times 268,43-1150 \times 600=0$

$\mathrm{Ld}=284,73 \mathrm{~mm}$

Böylece denge ağırlığı (Wd), A noktasından $284,73 \mathrm{~mm}$ uzaktayken sistem teorik olarak dengededir (Şekil 2).

Sistemi yorulma testlerinde kullanabilmek için skala kolunu $50 \mathrm{MPa}$ gerilmeye karşılık gelen bölüntülere ayrılmıştır. $50 \mathrm{MPa}$ gerilme oluşması için hareketli ağırlığın (Wh), skala kolu üzerinde ne kadar hareket ettirileceği $(\Delta \mathrm{L})$ bulunmuştur. Eğilme gerilmesi formülünden, ilk önce çatala uygulanan kuvvet tayin edilmiştir.

$\sigma=\frac{M \times C}{I}$

$\sigma:$ Eğilme gerilmesi $\left(\mathrm{N} / \mathrm{mm}^{2}=\mathrm{MPa}\right)$

I: Atalet momenti 


$$
\sigma=\frac{F x L \times(d / 2)}{\frac{\pi \times d^{4}}{64}}
$$

$\mathrm{M}=\mathrm{F} \times \mathrm{L}$

$\mathrm{C}=\mathrm{d} / 2$

$I=\frac{\pi \cdot d^{4}}{64}$

M: Eğilmeye etki eden eğilme momenti (N.mm) F: Numuneyi eğmeye zorlayan kuvvet $(\mathrm{N})$ d: Numune çapı (mm)

Formülün sadeleșmiș şekli:

$$
\sigma=10,18 \times \frac{F \times L}{d^{3}} \quad \mathrm{~N} / \mathrm{mm}^{2}(\mathrm{MPa})
$$

Sistemdeki verileri ve $50 \mathrm{MPa}$ gerilmeyi formülde uygularsak;

$$
50=10,18 \times \frac{F \times 228,9}{3,8^{3}} \quad \mathrm{~F}=1,17 \mathrm{~N}
$$

şeklinde buluruz.

Tasarım ve imalatı yapılan sistemde $50 \mathrm{Mpa}$ gerilme elde etmek için şekil 2'de görülen çatala $1,17 \mathrm{~N}$ kuvvet uygulanması gerekmektedir. $\mathrm{Bu}$ aşamada her bir $50 \mathrm{Mpa}$ gerilme için $(\mathrm{F}=1,17 \mathrm{~N})$ hareketli ağırlığın ne kadar hareket ettirileceği Eşitlik 8-10'dan hesaplanmıştır.

$\Sigma \mathrm{MA}=0$

$\mathrm{F} \times \mathrm{LAB}=\mathrm{Wh} \times \Delta \mathrm{L}$

$F=\frac{W_{h} \times \Delta L}{L_{A B}}$

$$
\Delta L=\frac{F \times L_{A B}}{W_{h}}
$$

$\mathrm{Wh}=2000 \mathrm{~g}=2 \mathrm{Kg}$
$\mathrm{Wh}=2 \times 9,806=19,612 \mathrm{~N}$

$$
\Delta L=\frac{1,17 \times 600}{19,612}=36,008 \mathrm{~mm}
$$

Yapılan sayısal çözümleme hareketli ağırlığın 36,008 mm'lik her hareketinde, yorulma deney numunesine $50 \mathrm{Mpa}$ gerilme uygulayacağını göstermektedir (Çizelge 1).

Çizelge 1. Skala kolu üzerinde gerilme-uzaklık çizelgesi

\begin{tabular}{|c|c|}
\hline$\sigma(\mathrm{MPa})$ & $\Delta \mathrm{L}(\mathrm{mm})$ \\
\hline 0 & $\mathrm{~L} 0$ \\
\hline 50 & $\mathrm{~L} 0+36,008$ \\
\hline 100 & $\mathrm{~L} 0+72,016$ \\
\hline 150 & $\mathrm{~L} 0+108,024$ \\
\hline 200 & $\mathrm{~L} 0+144,032$ \\
\hline 250 & $\mathrm{~L} 0+180,04$ \\
\hline 300 & $\mathrm{~L} 0+216,048$ \\
\hline 350 & $\mathrm{~L} 0+252,056$ \\
\hline$\ldots$ & $\ldots$ \\
\hline
\end{tabular}

Deney düzeneğinde kullanılan AC motor $220 \mathrm{~V}$, $450 \mathrm{Watt}, 9200 \mathrm{dev} / \mathrm{dk}$ özelliklerine sahiptir.

Motorun bu devirde dönmesi halinde, oluşabilecek vibrasyon ve oluşabilecek tehlikeli olumsuz etkilerden dolay1 numunenin dönme hız1 1000-9000 dev/dk olmasi uygun olacaktır [17]. Bu nedenle Şekil 3'de görülen yapı kasnaklar ve kayış yardımıyla sistemin dakikadaki devir sayısını düşürecek şekilde tasarlanmıştır.

Dm: Motorun çıkış miline bağlı olan kasnağın çapı (mm),

Dk: Numunenin bağlı olduğu mili döndüren, kasnağın çapı (mm),

Nm: Motorun devir sayısı (dev/dakika),

Nk: Kasnağın çapı (dev/dakika),

Dm: $20 \mathrm{~mm}$

Dk: $80 \mathrm{~mm}$

Nm: $9200 \mathrm{dev} / \mathrm{dk}$

$\mathrm{Nk}:$ ? dev/dk

$\mathrm{Nm} \times \mathrm{Dm}=\mathrm{Nk} \times \mathrm{Dk}$ 
$9200 \times 20=\mathrm{Nk} \times 80$

$\mathrm{Nk}=2300 \mathrm{dev} / \mathrm{dk}$

Eşitlik (7)'de yararlanarak sistemin dakikadaki devir sayısı $2300 \mathrm{dev} / \mathrm{dk}$ olarak hesaplanmıştır.

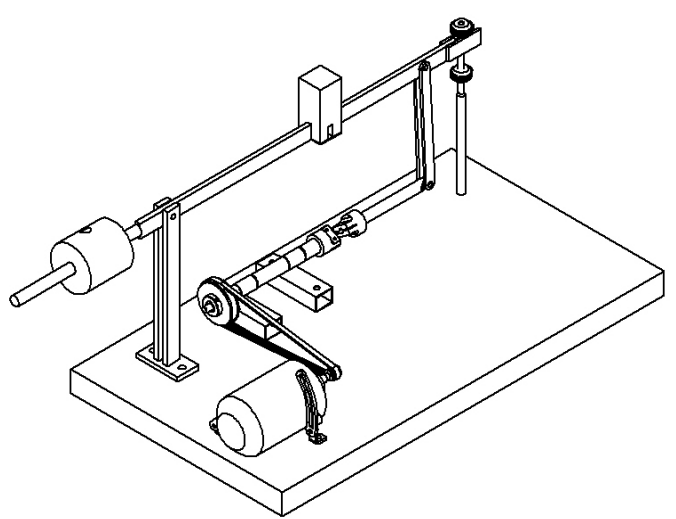

Şekil 3. Deney düzeneğinin izometrik görünüşü

\subsection{Mikro Denetleyici Kontrollü Devir Sayacı}

PIC16F84 mikro denetleyicisi kullanılarak oluşturulan devir sayıcı sistem Şekil 4'de verilmiştir. Sistem güç katı, optik alıcı-verici katları, BAŞLA, DUR, RESET butonları, LCD ve saymanın bittiğini mikro kontrole ileten SON butonu ve sesli bazır-ışıklı uyarı sitemi bölümlerinden oluşmaktadır. Mikro denetleyiciyi programlamak için "PIC BASIC PRO" programlama dili kullanılmıştır. "PIC BASIC PRO" programlama dilinde yazılan program Micro Code Studio programiyla .HEX uzantılı kodlara dönüştürülmüştür. Elde edilen .HEX uzantılı program kodları IC-Prog yazılımı kullanılarak PIC Programmer üzerinden PIC 16F84 mikro denetleyicisini içerisindeki hafizaya yüklenmiştir.

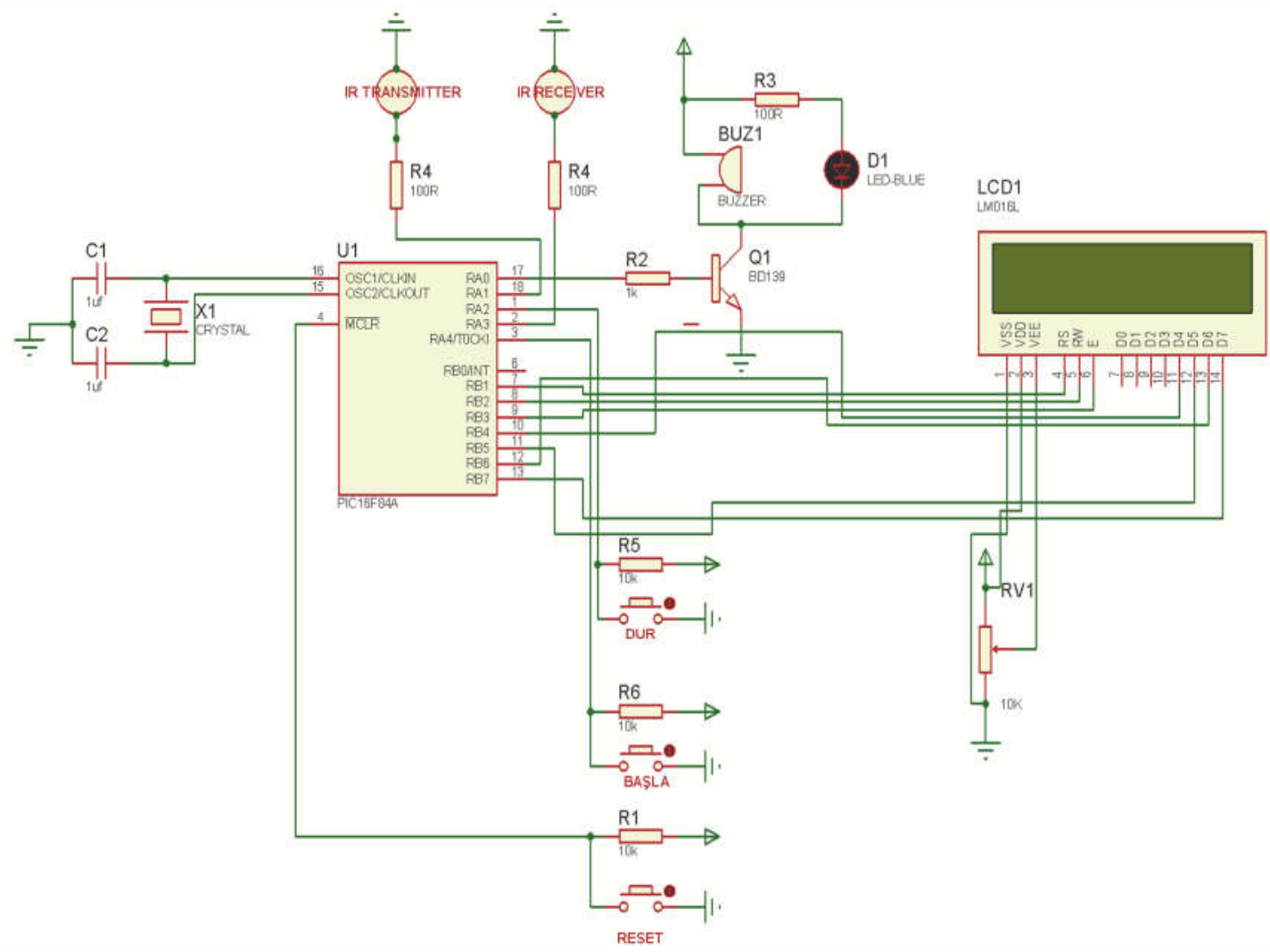

Şekil 4. PIC16F84 Mikro denetleyicili devir sayıcı devre 


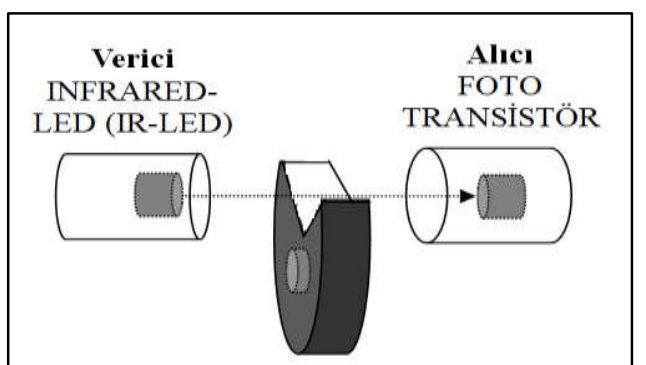

Şekil 5. Alıcı-verici yapısının şematik görünüşü

İnfrared led (IR-LED) doğru polarmada çalışan, insan gözünün görmediği (dalga boyu 820-1000 nm) kızılötesi 1şı̆̆ 1 yayan diyotlardır. IR-led çalışma gerilimi yaklaşık $1,25 \mathrm{~V}$ ve çalışma akımı
20 mA'dir. Çok az enerji harcarlar, yüksek yayım hızına sahiptirler, parazitlerden etkilenmezler, yüksek kararlılıkla çalışırlar.

Foto-transistör üzerinde bulunan mercek, 1şı̆̆1 odaklar ve PN birleşim yüzeyine düşürür. Fototransistör üzerine 1ş1k düştüğünde kollektör üzerinde akım akışı gerçekleşir ve transistör iletime geçer. Işık düşmezse yeterli beyaz akımı akmaz ve foto-transistör yalitkan olur. Burada sayımın doğru olarak yapılabilmesi için alıcı-verici mesafesi boru içi boşluk dâhil 16 mm alınmıştır ve alıc1-vericinin yerden yükseklikleri $118 \mathrm{~mm}$ olarak eşit tutulmuştur.

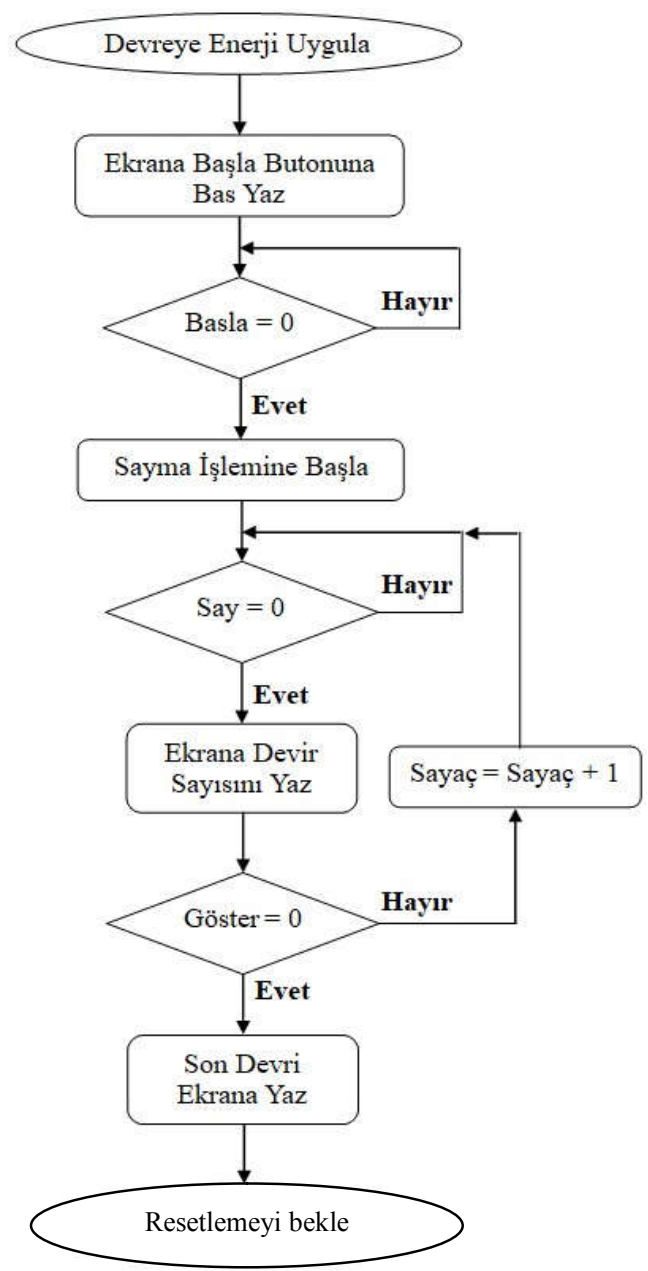

Şekil 6. Program işaret akış diyagramı 
Ayrıca, alıcı ve vericinin dıș ortamdaki 1 șıtan etkilenmemesi için boru içerisine yerleştirilmiştir. Sistemin çalışmasına ilişkin program işaret akış diyagramını gösteren algoritma Şekil 6'da verilmiştir. Motorun her bir devrinde kasnağa bağlı azaltılmış hız, sisteme bağlı Şekil 5'de verilmiş olan siyah diski döndürmektedir. 30 derece açı boşluğu bulunan disk her turda IR-LED' in yaydığ 1şığ1 foto-transistör üzerine düşmesi için yeterli süreyi tanır. Sistemin çalıştırılmasıyla birlikte, foto- transistör üzerine düşen 1 ş1k transistörün iletime geçmesini sağlar ve mikro denetleyici bunu algılayarak sayıcıyı sıfırdan başlatıp her seferinde bir artırır. Bu işlem yorulma testi yapılan deney numunesinin kırılıp durdurma anahtarının konumunu değiştirmesine kadar devam eder. $\mathrm{Bu}$ konum değiştirme mikro kontroller tarafinda algılanır ve toplam devir sayısı LCD ekranında gösterilir. Sistem resetlenerek farklı numuneler için hazır hale gelmektedir.

\subsection{Deneysel Çalıșmalar}

Yorulma test cihazında yorulma test edilen deney numunesi boyutları Şekil 7'deki gibi hazırlanmıştır [15].

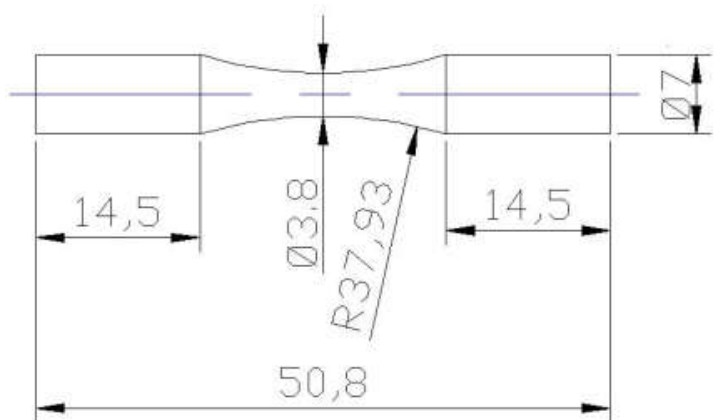

Şekil 7. Yorulma deneyi numune ölçüleri

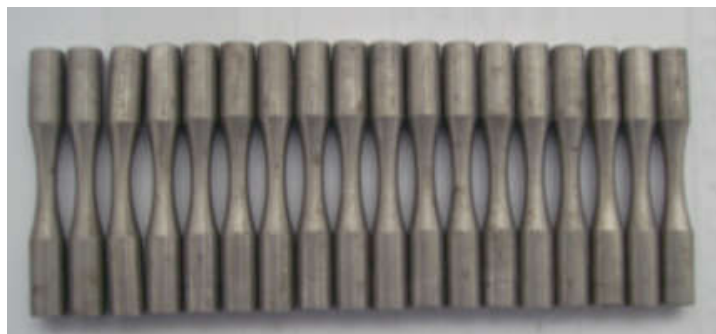

Şekil 8. Yorulma testi numuneleri
Yorulma testine tabi tutulan malzeme otomat çeliğidir. Malzemenin temin edildiği firmanın, otomat çeliğinin kimyasal kompozisyonu ile ilgili katalog değerleri Çizelge 2'de verilmiştir. Malzemenin element analizi ise Çizelge 3'deki gibidir. Hazırlanan numunelerin bir kısmı, $900{ }^{\circ} \mathrm{C}$ ' de 3 saat bekletilerek isıl işlem uygulanmıştır. Böylece ilgili şartlarda 1sıl görmüş otomat çeliğinin yorulma ömrü de incelenerek, isıl işlem görmemiş otomat çeliğinin yorulma ömrü ile karşılaştırılmıştır.

Çizelge 2. Otomat çeliği alınan firmadan temin edilen ilgili malzemenin kimyasal kompozisyonu

\begin{tabular}{|l|l|l|l|l|}
\hline $\mathbf{C}$ & Si & Mn & P & S \\
\hline 0,074 & 0,005 & 1,203 & 0,045 & 0,294 \\
\hline $\mathbf{C r}$ & $\mathbf{M o}$ & $\mathbf{N i}$ & $\mathbf{C u}$ & $\mathbf{P b}$ \\
\hline 0,04 & 0,02 & 0,08 & 0,12 & 0,30 \\
\hline
\end{tabular}

Çizelge 3. Yorulma testine maruz bırakılmış parçanın element analizi sonuçları

\begin{tabular}{|l|l|l|l|l|l|}
\hline C & Si & Mn & P & S & Cr \\
\hline 0,066 & 0,003 & 0,705 & 0,694 & 0,138 & 0,033 \\
\hline Mo & Ni & $\mathbf{C u}$ & $\mathbf{P b}$ & $\mathbf{C o}$ & $\mathbf{F e}$ \\
\hline 0,012 & 0,020 & 0,050 & 0,145 & 0,016 & 98,43 \\
\hline
\end{tabular}

Yorulma testi yapılan numunede uygulanan gerilme, çekme dayanımına yakın bir noktadan başlanmıştır. Gerilme belirli aralıklarla düşürülerek testler tekrarlanmış ve tekrar sayıları belirlenmiştir. Malzemenin çekme mukavemeti, katalog değerine göre $587 \mathrm{~N} / \mathrm{mm}^{2}$ 'dir. Ayrıca çalışılan otomat çeliğine, ilgili standarda göre numuneler hazırlanarak çekme testi uygulanmıştır [16]. İki çekme testi sonucu ise $605,13 \mathrm{~N} / \mathrm{mm}^{2}$ ve $558 \mathrm{~N} / \mathrm{mm}^{2}$ olmak üzere ortalama $581,5 \mathrm{~N} / \mathrm{mm}^{2}$ 'dir (Şekil 9).

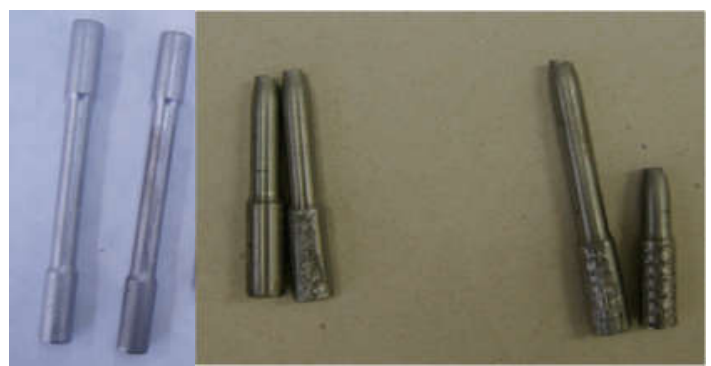

Şekil 9. Çekme testi numuneleri 
İlk yorulma testi için gerilme değeri olarak $550 \mathrm{~N} / \mathrm{mm}^{2}$ seçilmiştir. Gerilme değeri, daha önce bölümlediğimiz skala kolu üzerinde ayarlanmıştır. Yorulma testi $\mathrm{R}=-1$ gerilme oran 1 altında yapılmıştır. Şekil 7'de görüldüğü gibi bölüntü kolu test düzeneği tablasına paralel haldeyken, numune test düzeneğine yerleştirilmiştir.

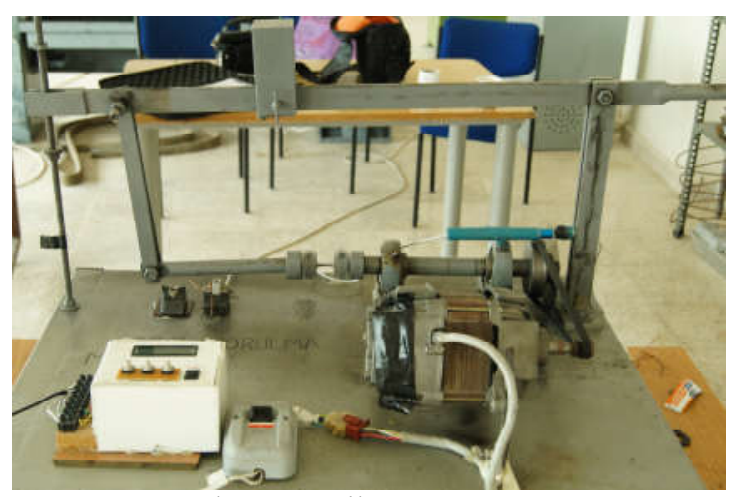

Şekil 10. Yorulma test cihazı

Test başladıktan sonra; mikro denetleyicili devir sayacının, infrared-led ve foto transistör aracılığıyla gerilme tekrar sayısı kayıt altına alınmıştır. Kımo-kct 100 modelli takometre ile çalışma anında tekrar sayısı kontrol edilerek mikro denetleyicinin kayıtları ile karşılaştırılmıştır (Şekil 11). Mikro denetleyici ile takometreden alınan sonuçlar arasında sapma gözlenmemiştir. Test başlarken devir sayısının $1436 \mathrm{dev} / \mathrm{dk}$ olduğu görülmüş; test sonunda ise bu sayının 1511 dev/dk’ya kadar çıktığı tespit edilmiştir.

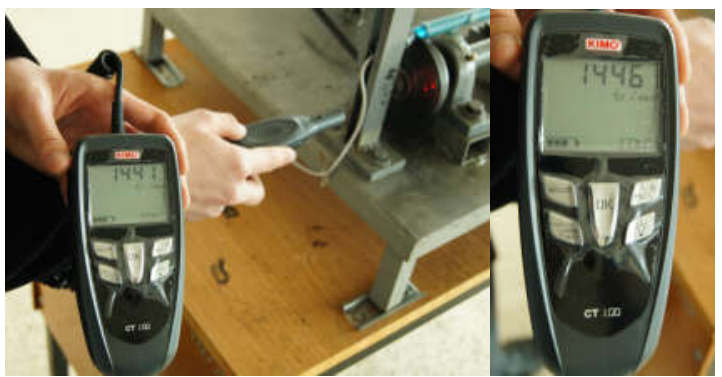

Şekil 11. Devir ölçer ile sistemin dakikadaki devir sayısının kontrolü

Yorulma testinde belirli bir tekrar sayısından sonra numune kırılmıştır. Şekil 12'de görüldüğü gibi mandren kolunun hemen altına konumlandırılmıs durdurma anahtarı sayesinde, devir ölçer son devir sayısını kaydederek saymayı durdurmaktadır.

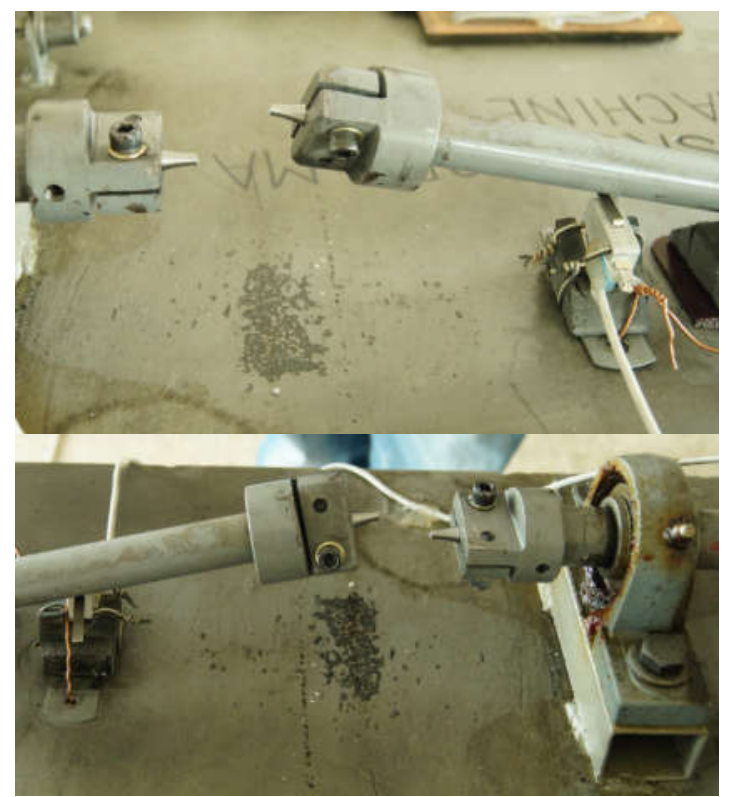

Şekil 12. Numunenin kırılması ve devir ölçer durdurma anahtarı

Yorulma deneyleri $550 \mathrm{~N} / \mathrm{mm}^{2}$ ile başlanmış ve deney serisi gerilmenin $500 \mathrm{~N} / \mathrm{mm}^{2}, 450 \mathrm{~N} / \mathrm{mm}^{2}$, $400 \mathrm{~N} / \mathrm{mm}^{2}, 350 \mathrm{~N} / \mathrm{mm}^{2}, 300 \mathrm{~N} / \mathrm{mm}^{2}$ olduğu değerlerde 2'şer test olmak üzere devam ettirilmiştir.

\section{SONUÇLAR VE ÖNERILER}

Geliştirilen "silindirik malzemelerde mikro denetleyicili yorulma test cihazı" ile 1sıl işlemsiz ve yüksek 1sıya maruz bırakılmış otomat çeliğinin yorulma ömürleri başarıyla tayin edilmiştir. Uygulanan gerilmelerde 2 test gerçekleştirilmiş ve bu testlerin ortalamaları alınmıştır.

Mikro denetleyici ile yorulma testi esnasında tekrar sayıları kayıt edilebilmektedir. Deney düzeneğinde kullanılan elektrik motorunun deney başlangıcında ve sonrasında devir sayısı değişmektedir. Deneylerde, sistem farklı numunelere bağlı olarak 1430-1440 dev/dk aralığında çalışmaya başlamıştır. Yaklaşık $10 \mathrm{dk}$ 
sonra devir sayısı farklı numuneler için 1500-1520 dev/dk arasında seyretmiştir. Motor devir sayısı tasarlanan mikro denetleyicili devir ölçer ile ölçülmüştür. Kımo-kct 100 modelli devir ölçer ile de ölçüm sonuçları doğrulanmıştır.

Sistem, motora etkiyen karşı kuvvetler (yük altımda çalıştırılması) nedeniyle daha düşük devir/ dakika'da çalışmaya başlamıştır. Sisteme etkiyen karşı kuvvetlerin, numunelerin yıpranmasına bağlı olarak değişmesi sonucunda sistem 1500-1520 dev/dk aralığında çalışmıştır. Motora numune bağlı değilken, Eşitlik 8 'de verilen hesaplamalar sonucunda sistemin $2300 \mathrm{dev} / \mathrm{dk}$ ile çalışacağı görülmüştür. Fakat numunenin bağlanıp motora etkiyen karşı kuvvetin oluşumu ile sistem ortalama $1510 \mathrm{dev} / \mathrm{dk}$ çalışmıştır.

\subsection{Materyal}

Temel boyutunun, B taşıma kapasitesi faktörü, $\mathbf{N}_{\gamma}$ üzerindeki etkisi ile ilgili ilk çalışma Debeer [9] tarafından gerçekleştirilmiştir. Temel genişliğinin artmasıyla, $\mathrm{N}_{\gamma}$ değerinin azalması Debeer [9] tarafından ölçek etkisi olarak adlandırılmıştır. Temel zemini; homojen, izotrop ve yarı sonsuz kabul edilmiştir. Temel zemini; homojen, izotrop ve yarı sonsuz kabul edilmiştir.

Tatsoukave arkadaşları [11] taşıma kapasitesi faktörü, $\mathrm{N}_{\gamma}$ ile temel boyutu arasındaki ilişkide iki faktörün etkili olduğunu belirtmişlerdir. Bunlardan ilki, Golder [12] tarafindan tanımlanan kumun mekanik özelliklerinin gerilme seviyesine bağımlılığı, ikincisi ise, dane boyutu etkisidir (Çizelge 1).

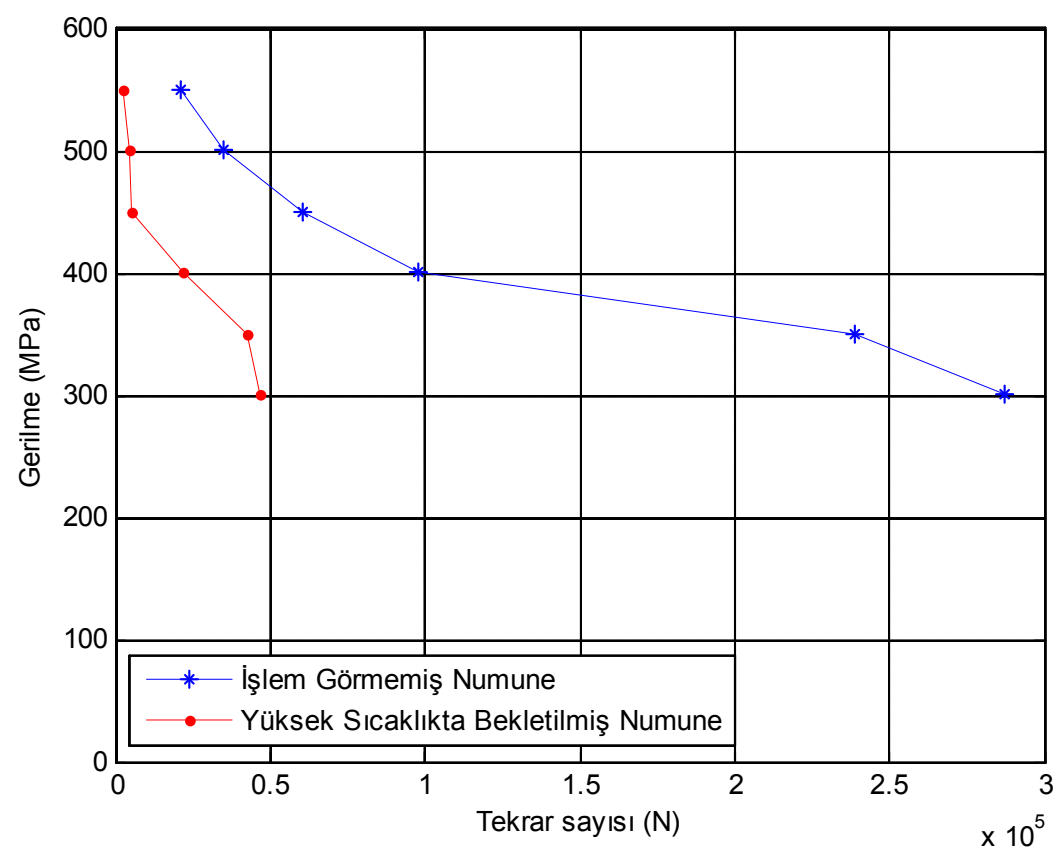

Şekil 13. İşlem görmemiş ve yüksek sıcaklıkta bekletilmiş otomat çeliği yorulma deneyi $\sigma-\mathrm{N}$ eğrisi

Şekil 13'de görüldüğü gibi yüksek sıcaklık ortamında bekleyen otomat çeliğinin yorulma ömürleri azalmaktadır.

Yorulma ömründeki azalmanın nedeni otomat çeliğinin 3 saat süreyle $900{ }^{\circ} \mathrm{C}$ 'de bekletilmesiyle mikro yapıda oluşan aşırı yaşlanmadır. Yaşlanma sıcaklık ve zamana bağlı olarak ortaya çıkmaktadır [4]. Sicaklık ve zamanın bir fonksiyonu olan yaşlanma sonucu, çelik yapısındaki alaşım elementleri çökelme mekanizması nedeniyle bir araya gelerek Şekil 14'deki gibi topaklanmıştır. Bu 
durum ise yorulma ömrünün azalmasına sebep olmuştur.

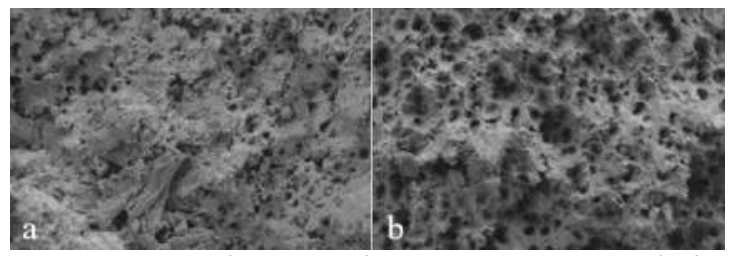

Şekil 14. Yorulma testi sonrası numunelerin kırılma yüzeylerinin SEM (500x) fotoğrafları a) İşlem görmemiş numune b) Yüksek sicaklıkta bekletilen numunenin mikro yapısında oluşan topaklanma-irileşme

Şekil 14 'de işlem görmemiş numune ile $900{ }^{\circ} \mathrm{C}$ 'de 3 saat bekletilmiş numunenin mikro yapıları bir arada verilmiştir. Şekilde yüksek ısıda bekletilen otomat çeliğinde meydana gelen çökelme görülmektedir.

Yüksek sicaklığın olduğu ortamlarda otomat çeliklerinin kullanılması uygun değildir.

Sıcaklık ile yorulma davranışı ters orantılıdır.

\section{KAYNAKLAR}

1. Yılmaz, S.S., Ünlü, B.S., Varol, R., 2007. Borlamanın Demir Esaslı T/M Malzemelerde Yorulma Davranışına Etkisi, Celal Bayar Üniversitesi Fen Bilimleri Dergisi, 3(1), 1-3.

2. Bhushan, B., Gupta, 1991. B.K., Handbook of Tribology, McGraw-Hill Inc., USA.

3. Black, J.T., Kohser, R.A., 2007. Materials and Process in Manufacturing, John Wiley \& Sons.

4. Kalpakjian, S., 2001. Manufacturing Engineering and Technology, Addison Wesley, USA.

5. Groover, M. P., 2007. Fundamentals of Modern Manufacturing, John Wiley \& Sons, USA.

6. McKelvey, S.A., Fatemi, A., 2011. Surface Finish Effect on Fatigue Behaviour of Forged Steel, International Journal of Fatigue, 36(1), 130-145.
7. Suh, C.M., Suh, M. S., Hwang N.S., 2012. Growth Behaviour of Small Surface Fatigue Cracks in AISI 304 Stainless Steel, Fatigue \& Fracture of Engineering Materials \& Structures, 35(1), 22-29.

8. Şengül, A. B., Çelik, A., 2012. Farklı Çevrim Sayılarında Uygulanan Aşırı Yüklemenin Oluşturduğu Yorulma Çatlak İlerleme Gecikmesi Üzerinde Plazma Nitrürlemenin Etkisi, Gazi Üniversitesi MühendislikMimarlık Fakültesi Dergisi, 27(4), 707-715.

9. Jin, O., 2000. The Characterization of Small Fatigue Crack Growth in PH13-8 Molybdenum Stainless Steel, Doktora Tezi, Georgia University, Instuty of Technology.

10. Aviles, R., Albizuri, J., Lamikiz, A., 2011. Influence of Laser Polishing on the High Cycle Fatigue Strength of Medium Carbon AISI 1045 Steel, International Journal of Fatigue, 33(11), 1477-1489.

11. Shen, H., Guo, W., 2011. 3D Fracture Mechanichs Investigation Surface Fatigue Crack Propagation, Fatigue \& Fracture of Engineering Materials \& Structures, 34(9), 682-688.

12. Saygın, M., 2006. AISI 1020 Çeliklerinde Borlamanın Yorulma Dayanımına Etkisi, Yüksek Lisans Tezi, Osman Gazi Üniversitesi, Fen Bilimleri Enstitüsü.

13. Yaşar, M., 2007. Dizel Otomobil Pompa Milinin Yorulma Kırılması Analizi, 8. Uluslararası Kırılma Konferansı Bildiriler Kitab1, İstanbul, 544-553, 7-9 Kasım.

14. Gönen, D., Oral, A., Çakır, M. C., 2008. Çift Sıkıştırma Oranlı Yay Yorulma Test Cihazı Tasarım ve İmalatı, Balıkesir Üniversitesi Fen Bilimleri Enstitüsü Dergisi, 10(1), 98-108.

15. Türk Standartlar Enstitüsü, 2002. MetallerDönen Çubuk Eğme Yorulma Deneyleri, TS ISO 1143, Ankara.

16. Türk Standartları Enstitüsü, 2011. Metalik Malzemeler -Çekme Deneyi- Bölüm 1: Oda Sicaklığında Deney Metodu, TS EN ISO 68921, Ankara. 